
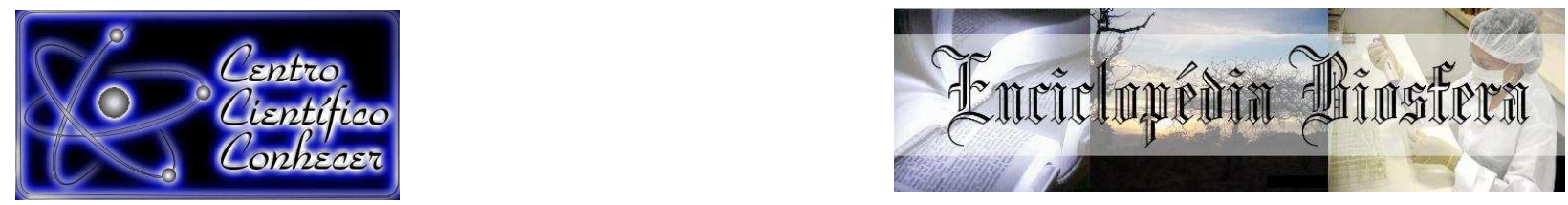

\title{
LEVANTAMENTO DA OCORRENCIA DE HPV (Papilomavírus Humano) EM EXAMES COLPOCITOLÓGICO NO CAIS MULHER - ANÁPOLIS - GO
}

\footnotetext{
Daniela de Fatima Sousa ; Jeice Maria de Oliveira²; Weniclézia Divina Gomes $^{3}$; Renan de Souza Soares ${ }^{4}$; Ariana Alves Rodrigues ${ }^{5}$

${ }^{1,2,3}$ Acadêmica do Curso de Biomedicina, Anhanguera Educacional, Anápolis ${ }^{4}$ Mestrando do Programa de Pós-Graduação em Ciências Ambientais, Pró-reitora de Pesquisa, Universidade Federal de Goiás

${ }^{5}$ Doutoranda do Programa de Pós-Graduação em Ciências Ambientais, Pró-reitora de Pesquisa, Universidade Federal de Goiás (ariana.biomed@gmail.com) Goiânia, Brasil

Recebido em: 08/09/2015 - Aprovado em: 14/11/2015 - Publicado em: 01/12/2015 DOI: http://dx.doi.org/10.18677/Enciclopedia_Biosfera_2015_042
}

\begin{abstract}
RESUMO
O papilomavírus humano (HPV) é considerado uma doença sexualmente transmitida com maior prevalência e incidência do mundo. O estudo teve por objetivo investigar a infecção pelo HPV em mulheres que realizaram colpocitológico no CAIS mulher de Anápolis/GO no período de julho de 2012 à julho de 2014. Utilizou-se como recurso metodológico pesquisa documental, descritiva e quantitativa. Dos 10.984 prontuários analisados, $2.4 \%$ das mulheres possuíam infecção pelo HPV, destacando principalmente as mulheres de 38 a 49 anos (35\%). Não existem dados na literatura que associem a infecção do HPV com sazonalidade. A transmissão estaria associada a fatores como: vida sexual precoce, a falta de uso de preservativos, número elevado de parceiros sexuais, gestações, uso de anticoncepcionais, tabagismo e imunodeprimidos.
\end{abstract}

PALAVRAS-CHAVE: Colpocitológico; infecção; mulheres; papilomavírus humano (HPV); vida sexual

\section{SURVEY OF THE OF HPV (Human Papillomavirus) OCCURRENCE WITH PAP SMEAR IN CAIS MULHER - ANÁPOLIS - GO}

\section{ABSTRACT}

Human papillomavirus (HPV) is considered one of the sexually transmitted diseases with the highest prevalence and incidence in the world. The study aimed to investigate HPV infection in women who had Pap smear in CAIS Mulher from Anapolis/GO from July 2012 to July 2014. It was used as a methodological feature documentary, descriptive and quantitative research. Of the 10.984 records analyzed, $2.4 \%$ of women had HPV infection, especially highlighting women $38-49$ years (35\%). There are no data in the literature linking HPV infection with seasonality. The transmission would be associated with factors such as early sexual life, lack of condom use, high numbers of sexual partners, pregnancies, contraceptive use, smoking and immunocompromised.

KEYWORDS: Colpocytologic; infection; papillomavirus (HPV); sexual life; women 


\section{INTRODUÇÃO}

O Papilomavírus humano (HPV) é um vírus DNA dupla fita, não envelopado, pertencente à família Papillomaviridae, cujo genoma é circular e sua partícula viral tem formato icosaédrico com 72 capsomêros. É um agente frequentemente adquirido por via sexual que acomete a pele ou as mucosas. A maioria das infecções por esse vírus é benigna formando verrugas genitais, enquanto pequena parte está associada ao desenvolvimento de câncer do colo de útero (VERONESI \& FOCACCIA, 2005; GIRIANELLI et al., 2010; SANTOS et al., 2011).

Cerca de 291 milhões de mulheres no mundo são portadoras do vírus, 32\% estão infectadas pelos tipos 16 e 18 ou ambos, fato que caracteriza o HPV como uma das doenças sexualmente transmitidas (DST) com maior prevalência e incidência do mundo. O HPV é considerado o agente etiológico central envolvido na gênese dos tumores cervicais, estima-se que a cada 100 mil mulheres que são diagnosticadas, 18 delas desenvolvem o câncer de colo de útero (BORSATTO et al., 2011; BRASIL, 2011; CHAGAS \& NEVES, 2013).

Atualmente existem mais de 100 tipos de HPVs, sendo que cerca de 40 tipos podem infectar o trato genital. Pelo menos 15 possuem potencial oncongênico, apresentando maior risco ou probabilidade de provocar infecções persistentes e estar associados a lesões precursoras de neoplasias (HINRRICHSEN, 2005; BORSATTO et al., 2011).

De acordo com o potencial carcinogênico os HPVs são divididos em três classes: baixo risco, risco intermediário e alto risco. Dentro dos considerados de alto risco, destacam-se os subtipos 16 e 18 que são responsáveis por $70 \%$ dos cânceres cervicais. Já os de baixo risco estão relacionados a lesões não oncogênicas, sendo os subtipos 06 e 11 responsáveis por $90 \%$ de condilomas genitais e papilomas laríngeos (SOUSA et al., 2008; BRASIL, 2011; CHAGAS \& NEVES, 2013).

A taxa de contaminação pelo HPV é maior nos primeiros anos de atividade sexual, entre 18 a 28 anos, e a principal porta de entrada deste vírus é decorrente do não uso de preservativos, número elevado de parceiros sexuais e gestações, uso de anticoncepcionais, tabagismo, vida sexual precoce e imunodepressão (RAMA et al., 2008; AYRES \& SILVA, 2010; TRISTÃO et al., 2012).

A transmissão do HPV diferente de outras DSTs, não ocorre pelo contato direto com o sangue e secreções corpóreas, a principal via de transmissão é o contato entre a pele ou mucosas de um indivíduo com a pele ou mucosa de indivíduos contaminados. Existem ainda outras vias de contaminação tais como a transmissão perianal, contato com mãos, objetos, banheiros, toalhas e roupas íntimas que estejam contaminadas pelo vírus (VERONESI \& FOCACCIA, 2005; SANTOS et al., 2011).

A maior parte de infecções causadas pelo HPV é de caráter assintomático ou inaparente, podendo assim regredir espontaneamente. Estima-se que $5.0 \%$ das pessoas contaminadas desenvolveram alguma forma de manifestação. As infecções normalmente podem se manifestar de duas maneiras: clínica ou subclínicas. As infecções clínicas são caracterizadas por lesões aparentes vascularizadas, na forma de condilomas e verrugas genitais geralmente conhecidas como crista de galo de tamanhos variáveis. As infecções subclínicas não são visíveis a olho nu, podendo ser encontradas nos mesmos locais e não apresentam nenhum tipo de sintoma ou sinal e são diagnosticadas por meio de exames laboratoriais (HINRICHSEN, 2005; VERONESI \& FOCACCIA, 2005; BRASIL, 2011).

Entre as formas de detecção do HPV destacam-se os métodos citopatológicos, os histopatológicos, os imunológicos e os moleculares. Na prática 
clínica a principal estratégia adotada é o colpocitológico, que permite detectar lesões precursoras causadas pelo HPV. Hoje no Brasil a metodologia de pesquisa por Reação da Cadeia de Polimerase (PCR) de HPV é considerada um padrão ouro para comprovar a existência do vírus HPV. Todas as mulheres que tem ou já tiveram vida sexual ativa e que estão entre 25 e 64 anos devem realizar esse exame. 0 mesmo pode ser realizado em postos de saúde da rede pública, sendo simples e indolor. Caso o resultado seja positivo, o exame deve ser repetido a cada seis meses para monitoramento (CHAGAS \& NEVES, 2013; INCA, 2014).

Até o presente momento não há um tratamento específico para eliminar o vírus, somente tratamentos para amenizar essas lesões como a remoção dos condilomas visíveis através de cauterizações, vaporização a laser, ácido tricloroacético (ATA) e medicamentos que melhoram o sistema imunológico. Existem dois tipos de vacinas para os tipos de HPV: a quadrivalente, para os tipos $6,11,16$ e 18 indicados para mulheres entre 9 e 26 anos; e a bivalente, para tipos 16 e 18 indicados para mulheres entre 10 e 25 anos de idade (BORSATTO et al., 2011; BRASIL, 2011; SANTOS et al., 2011).

A análise crítica dos estudos sobre as infecções pelo HPV na cidade de Anápolis pode contribuir com o conhecimento epidemiológico para o fortalecimento das políticas de controle do câncer do colo do útero. A falta de estudos regionais sistematizados sobre a magnitude desse problema impõe limitações para 0 planejamento das ações de vigilância e controle. O presente estudo objetivou investigar a infecção pelo HPV em mulheres que realizaram colpocitológico no CAIS mulher de Anápolis/GO no período de julho de 2012 à julho de 2014 e relacionar as possíveis variáveis do processo.

\section{MATERIAL E MÉTODOS}

Trata-se de um estudo documental, descritivo e de natureza quantitativa. A coleta de dados foi realizada em prontuários de mulheres que realizaram exames colpocitológicos no Cais Mulher da cidade de Anápolis-GO, período de julho de 2012 a julho de 2014.

A coleta de dados foi realizada nos prontuários disponíveis nos arquivos da instituição, foram considerados viáveis para o estudo os documentos que comprovavam a realização do colpocitológico, que estavam devidamente preenchidos, sem rasuras, legíveis e que não demandassem nova amostra. Obtevese um total de 10.984 prontuários que atendessem os critérios propostos e desses foram coletados dados referentes à infecção por HPV, idade, número de filhos e método contraceptivo utilizado.

Os dados foram analisados pela estatística descritiva e apresentados em forma de tabelas e gráficos, com a frequência das variáveis apresentadas em percentuais. Para tais cálculos foi utilizado o software Microsoft Excel 2010. O estudo obedeceu à resolução 196/96 do Conep, foi submetido ao comitê de ética em pesquisa da Associação Anhanguera Educacional LTDA de acordo como protocolo no $747.766 / 2014$.

\section{RESULTADOS E DISCUSSÃO}

No período de julho de 2012 a julho de 2014 no Cais Mulher em AnápolisGO, dos 10.984 prontuários analisados, $97.6 \%$ foram negativos para o vírus HPV e $2.4 \%$ de casos positivos, valores inferiores aos encontrados em outros estudos. No estudo apresentado por OLIVEIRA et al. (2013) na Unidade Básica de Saúde do Rio Grande do Sul encontraram positividade de 18,2\%, já RAMA et al. (2006) em São 
Paulo (SP) encontraram 16,8\%, GIRIANELLI et al. (2010) no Rio de Janeiro encontraram 17.8\%. Segundo AYRES \& SILVA (2010) estima-se que a prevalência populacional de infecção pelo HPV entre mulheres no Brasil varie entre $10,4 \%$ e $24,5 \%$.

Observa-se que o valor encontrado em Anápolis é menor que a média nacional, fato que pode ser explicado pelo baixo volume de pacientes atendidos na unidade de saúde quando comparados ao volume atendido em outros centros urbanos, bem como a sensibilidade do método utilizado para a detecção da infecção pelo vírus HPV. A instituição estudada utiliza como detecção de HPV o método colpocitológico, enquanto os outros autores estudados utilizaram a técnica de Biologia Molecular de Captura Híbrida II (FEDRIZZI et al., 2008).

A média etária da população estudada foi de 34,17 anos (DP 12,25), com a maior distribuição entre as faixas etárias de 38 a 49 anos com $35 \%$ dos casos e entre 14 a 25 anos com 29\% (Figura 1). Dados semelhantes foram encontrados por FEDRIZZI e colaboradores (2008) que obtiveram uma positividade maior em mulheres de 21 a 25 anos (38\%). TORRES et al. (2009) informam que quase $50 \%$ das mulheres sexualmente ativas entre 15 e 49 anos estão infectadas pelo HPV. NOMELINI et al. (2007) avaliaram pacientes na faixa etária de 15 a 74 anos e pode concluir que a infecção por HPV em mulheres jovens em geral, tende a regredir espontaneamente, enquanto que entre as mulheres mais velhas o vírus é mais propenso a persistir.

A incidência para a infecção do HPV em mulheres mais jovens têm ocorrido devido ao comportamento sexual, pois correlacionam fatores como: relacionamento sexual precoce, casamento em idade muito jovem, idade jovem na primeira gravidez, baixo uso de preservativos, atividades sexuais não planejadas, parceiros sexuais múltiplos e múltiplos casamentos (BRASIL, 2011; CHAGAS \& NEVES, 2013).

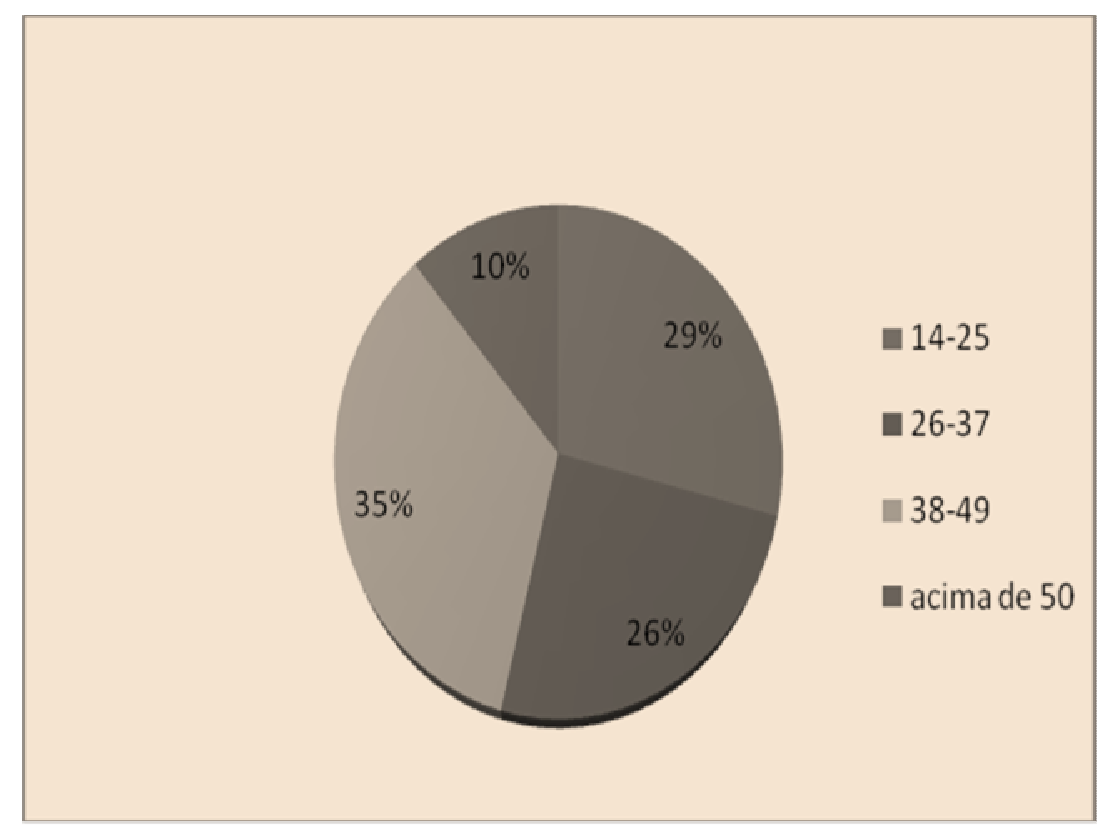

FIGURA 1. Faixa etária das pacientes que apresentaram positividade no exame colpocitológico para HPV no CAIS Mulher de Anápolis/GO no período de julho de 2012 à julho de 2014. 
Dos 263 casos positivos, $46 \%$ das mulheres possuem de um a dois filhos e $23 \%$ não possuem nenhum filho (Tabela 1). MURTA et al. (2001) não observaram relação entre a gestação e a frequência da infecção pelo HPV em adolescentes. Já estudos apresentados por SCHNEIDER et al. (1987) apontam a gravidez como um fator predisponente à infecção por HPV devido à imunomodulação ou influências hormonais. Isso pode explicar as porcentagens encontradas em mulheres com três ou quatro filhos (21\%) e acima de cinco filhos (10\%). O alto número de gestações ainda pode estar relacionado a um não uso de métodos contraceptivos de barreira, 0 que pode favorecer a transmissão do HPV (MARTINS et al., 2013).

Quando analisados os métodos contraceptivos utilizados, 30\% fazem uso de anticoncepcionais hormonais, $28 \%$ possuem laqueadura e $22 \%$ não utilizam nenhum dos métodos. Os demais métodos contraceptivos utilizados apresentam-se listados na Tabela 1. CARRENO et al. (2006) também obtiveram grande positividade $(48,2 \%)$ de portadoras de HPV que utilizavam anticoncepcionais hormonais. Anticoncepcionais hormonais alteram a microbiota vaginal, o que pode favorecer a contração do HPV pelas mucosas, além disso, podem atuar como cofatores na transformação de células e na progressão das lesões de baixo para alto grau. Já as mulheres com laqueadura não se preocupam mais com o risco de uma gravidez indesejada o que leva a falta do uso de preservativo (MURTA et al., 2001;LEITE et al., 2010).

Somente $2 \%$ das mulheres que usaram preservativos foram positivas para 0 HPV. Pode se destacar que a transmissão de agentes patológicos via sexual, só pode ser evitada mediante uso de preservativos. As possíveis causas de transmissão mesmo com preservativo devem-se ao mau uso e também pelo fato das lesões estarem não só no pênis, pois pode haver presença de infecção na vulva, na região pubiana, perineal e perianal ou na bolsa escrotal, regiões essas que 0 preservativo não cobre (ALVES \& LOPES, 2008; BRASIL, 2011).

TABELA 1. Distribuição de casos positivos para HPV associada às variáveis selecionadas em prontuários de mulheres atendidas no Cais Mulher Anápolis/GO.

\begin{tabular}{|c|c|c|c|}
\hline Variável & Categoria & $\mathrm{N}^{\circ}$ de casos HPV + & $\%$ HPV + \\
\hline \multirow[t]{4}{*}{$\mathrm{N}^{\circ}$ de Filhos } & Nenhum & 60 & $23 \%$ \\
\hline & 1 ou 2 & 121 & $46 \%$ \\
\hline & 3 ou 4 & 56 & $21 \%$ \\
\hline & acima de 5 & 26 & $10 \%$ \\
\hline \multirow[t]{10}{*}{ Contraceptivos } & Anticoncepcional & 79 & $30 \%$ \\
\hline & Laqueadura & 78 & $28 \%$ \\
\hline & Nada & 58 & $22 \%$ \\
\hline & Menopausa & 20 & $7 \%$ \\
\hline & Abs. Sexual & 11 & $4 \%$ \\
\hline & Marido Vasectomizado & 8 & $3 \%$ \\
\hline & Camisinha & 3 & $2 \%$ \\
\hline & Coito interrompido & 2 & $2 \%$ \\
\hline & DIU & 2 & $1 \%$ \\
\hline & Histerectomia & 2 & $1 \%$ \\
\hline
\end{tabular}


$\mathrm{Na}$ análise do número de casos por período, observa-se que os meses com maior número de casos são: agosto/2012 (7\%), outubro/2012 (7\%), janeiro/2013 (8\%) e março/2014 (7\%), enquanto julho/2013 (1\%), maio e julho/2014 (1\%) foram os meses com menores números (Figura 2). Entretanto não há a configuração de uma faixa de período de destaque de ocorrência da infecção, também não foi encontrado na literatura dados que associem a infecção do HPV com sazonalidade. A transmissão estaria associada a fatores como: vida sexual precoce, a falta de uso de preservativos, número elevado de parceiros sexuais, gestações, uso de anticoncepcionais, tabagismo e imunodepressão (RAMA et al., 2008; AYRES \& SILVA, 2010; TRISTÃO et al., 2012; GIRIANELLI et al., 2014).

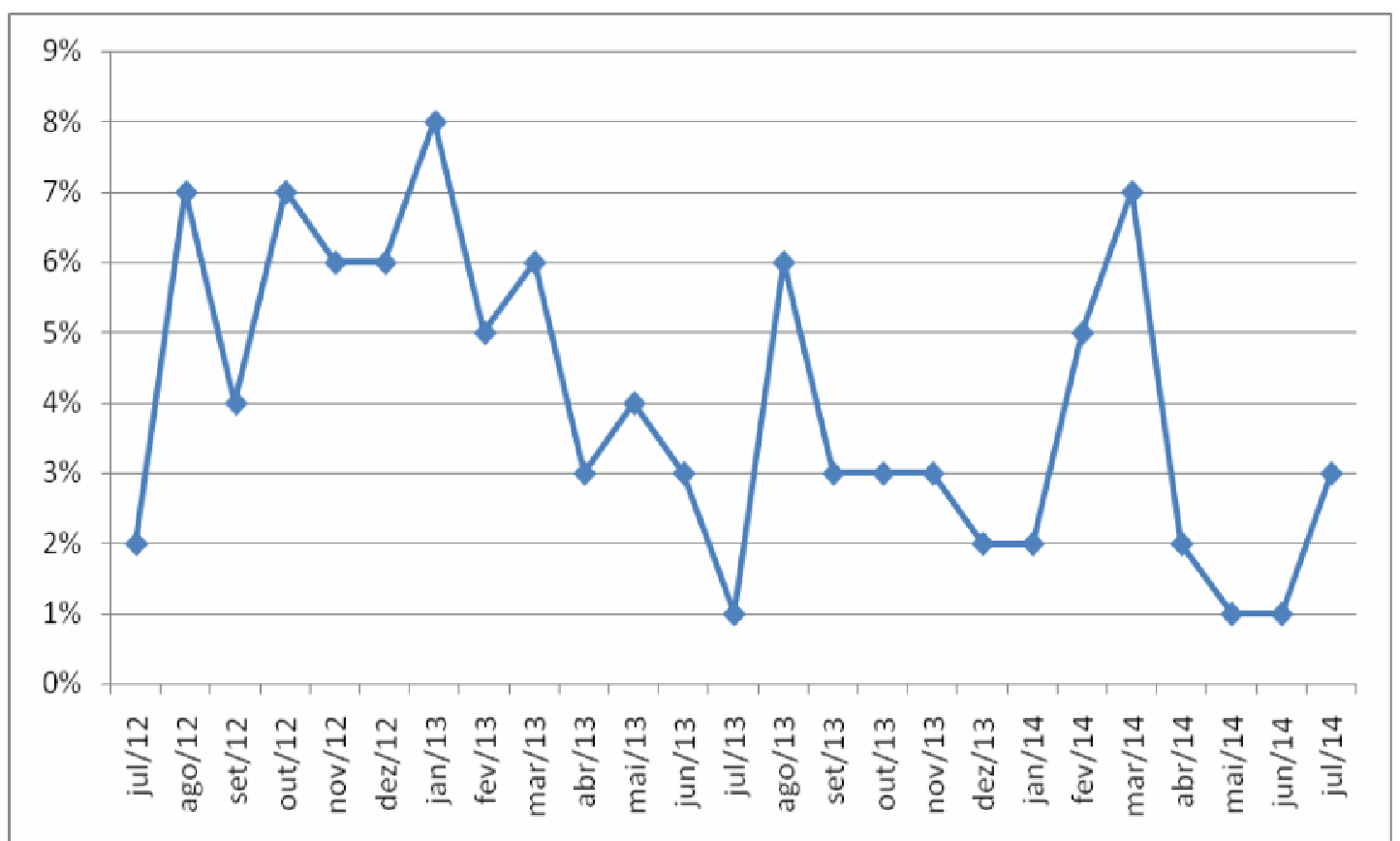

FIGURA 2. Análise do número casos e oscilações por período dos casos positivos para HPV em prontuários de mulheres atendidas no Cais Mulher Anápolis/GO.

\section{CONCLUSÃO}

No estudo foram analisados 10.984 prontuários, onde 2,4\% das mulheres possuíam infecção pelo Papilomavírus humano, sendo destacado principalmente em mulheres de 38 a 49 anos, apesar de essa incidência ser mais comum em mulheres mais jovens. A gravidez pode ser considerada um fator predisponente à infecção por HPV devido à imunomodulação ou influências hormonais. Pode-se concluir que a maioria das mulheres fazem uso de Anticoncepcionais hormonais e possuem laqueadura, o que sugere que essas mulheres deixam de usar preservativos por acharem que estão protegidas a uma gravidez indesejada, e não se preocupam com o fato de contrair HPV ou qualquer outra DST já que a principal porta de entrada e através da relação sexual. O HPV é considerado uma das doenças sexualmente transmitida com maior prevalência e incidência do mundo e há uma grande importância em combater a propagação desse vírus, pois o mesmo é a principal causador do câncer do colo do útero. 


\section{REFERÊNCIAS}

ALVES, A. S; LOPES, M. H. B. M. Uso de métodos anticoncepcionais entre adolescentes universitários. Revista Brasileira de Enfermagem, v. 61, n. 2, p.170$77,2008$.

AYRES, A. R. G.; SILVA, G .A. Prevalência de infecção do colo do útero pelo HPV no Brasil: revisão sistemática. Revista de Saúde Pública, v. 44, n. 5, p. 963-974, 2010.

BORSATTO, A. Z.; VIDAL, M. L. B.; ROCHA, R. C. N. P. Vacina contra o HPV e a Prevenção do Câncer do Colo Útero: Subsídios para a Prática. Revista Brasileira de Cancerologia, v. 57, n. 1, p. 67-74, 2011.

BRASIL. Ministério da Saúde. Biblioteca virtual em saúde. Condiloma acuminado (HPV). 2011. Disponível em:<http://bvsms.saude.gov.br/bvs/dicas/236_condiloma .html> Acesso em: 25 de mar. 2014.

CARRENO, I.; COSTA, J. S. D.; OLINTO, M. T. A.; MENEGHEL, S. Uso de métodos contraceptivos entre mulheres com vida sexual ativa em São Leopoldo Rio Grande do Sul, Brasil. Caderno de Saúde Pública, v. 22, n. 1, p. 1101-1109, 2006.

CHAGAS, L. L. P.; NEVES, J. B. Rastreamento do Papiloma Vírus Humano (HPV) em mulheres com mais de 25 anos. Revista de Enfermagem Integrada, v. 6, n. 1, p.1043-1052, 2013.

FEDRIZZI, E. N; SCHLUP, C. G.; MENEZES, M. E.; OCAMPOS, M. Infecção pelo Papilomavírus Humano (HPV) em Mulheres de Florianópolis, Santa Catarina. Jornal Brasileiro de Doenças Sexualmente Transmissíveis, v. 20, n. 2, p. 73-79, 2008.

GIRIANELLI, V. R.; THULER, L. C. S.; SILVA, G. A. Prevalência de HPV em mulheres assistidas pela Estratégia Saúde da Família na Baixada Fluminense do Estado do Rio de Janeiro. Revista Brasileira de Ginecologia e Obstetrícia, v. 32, n. 1, p. 39-46, 2010.

GIRIANELLI, V. R.; THULER, L. C. S.; SILVA, G. A. Prevalência de HPV em mulheres assistidas pela estratégia saúde da família na Baixa Fluminense do Estado do Rio de Janeiro. Revista Brasileira de Ginecologia e Obstetrícia. v. 32, n.1, p. 39-46, 2010.

GIRIANELLI, V. R.; GAMARRA, C. J.; AZEVEDO E SILVA, G. Os grandes contrastes na mortalidade por câncer do colo uterino e de mama no Brasil. Revista de Saúde Pública, v. 48, n. 3, p. 459-467, 2014.

HINRICHSEN, S. L. DIP- Doenças Infecciosas e Parasitária. Rio de Janeiro: Guanabara Koogan, p.1098, 2005.

INSTITUTO NACIONAL DE CÂNCER (INCA). Detecção Precoce. Colo do útero. 2014. Disponível em:<http://www2.inca.gov.br/wps/wcm/connect/tiposdecancer/site /home/colo_utero/deteccao_precoce>. Acesso em: 16 de mar. 2014. 
LEITE, S. R. R. F.; AMORIM, M. M. R.; LEITE, T. N. F.; OLIVEIRA, V. S; JUNIOR, J. F. A. A. F.; XIMENES, R. A. A. Perfil clínico e microbiológico de mulheres com vaginose bacteriana. Revista Brasileira de Ginecologia e Obstetrícia. v. 32, n. 2, p. 82-87, 2010.

MARTINS, A. C. N.; MARTINS, A. C. S.; FERRAZ, L. M. Papel do Enfermeiro na Prevenção de Infecção por HPV em Adolescentes e Jovens. In: Convibra Saúde Gestão e Promoção da Saúde, 2., 2013, . Anais Eletrônicos... Disponível em < http://www.convibra.com.br/upload/paper/2013/75/2013_75_7858.pdf>. Acesso em 8 set. 2015.

MURTA, E. F. C.; SOUZA, M. A. H.; ADAD, S. J.; JÚNIO, E. A. Infecção pelo papilomavírus humano em adolescentes: relação com o método anticoncepcional, gravidez, fumo e achados citológicos. Revista Brasileira de Ginecologia e Obstetrícia, v. 23, n. 4, p. 217-221, 2001.

NOMELINI, R. S.; BARCELOS, A. C. M.; MICHELIN, M. A.; ADAD, S. J.; MURTA, E. F. C. Utilização de método de papilomavírus humano na prevenção do câncer cervical em um hospital universitário. Caderno de Saúde Pública, v.23, n.6,p. 13091318, 2007.

OLIVEIRA, G. R.; VIEIRA, V. C.; BARRAL, M. F. M.; DOWICH, V.; SOARES, M. A.; GONÇALVES, C. V.; MARTINEZ, A. M. B. Fatores de risco e prevalência da infecção pelo HPV em pacientes de Unidades Básicas de Saúde e de um Hospital Universitário do Sul do Brasil. Revista Brasileira de Ginecologia e Obstetrícia, v. 35, n. 5, p. 226-32, 2013.

RAMA, C. H.; ROTELI-MARTINS C. M.; DERCHAIN, S. F. M.; OLIVEIRA, E. Z.; ALDROGHI, J. M.; MARIANI, N. C. Detecção sorológica de anti-HPV 16 e 18 e sua associação com os achados do papanicolaou em adolescentes e mulheres jovens. Revista da Associação Médica Brasileira, v. 52, n. 1, p. 43-47, 2006.

RAMA, C. H.; ROTELI-MARTINS, C. M.; DERCHAIN, S. F. M.; LONGATTO-FILHO, A.; GONTIJO, R. C.; SARIAN, L. O. Z.; SYRJANEN, K.; ALDRIGHI, J. M. Prevalência do HPV em mulheres rastreadas para o câncer cervical. Revista de Saúde Pública, v. 42, n. 1, p. 123-130, 2008.

SANTOS, I. M.; MAIORAL, M.F.; HAAS, P. Infecção por HPV em homens: importância na transmissão, tratamento e prevenção do vírus. Estudos de Biologia, v. 76, n. 1, p.111-118, 2011.

SCHNEIDER, A.; MEINHARDT, G.; DE VILLERS, E. M.; GISSMANN, L. Sensitivity of the cytologic diagnosis of cervical condyloma in comparison with HPV-DNA hydridization studies. Diagnostic Cytopathology, v. 3, p. 250-255, 1987.

SOUSA, L. B.; PINHEIRO, A. K. B.; BARROSO, M. G. T. Ser mulher portadora do HPV: uma abordagem cultural. Revista da Escola de Enfermagem da USP, v. 42, n. 4, p. 737-743, 2008. 
TORRES, L. M.; Páez, M., Insaurralde, A; Rodriguez, M. I.; Castro, A.; Kasamatsu, E. Detection of High Risk Human Papillomavirus Cervical Infections by the Hybrid Capture in Asunción, Paraguay. Brazilian Journal of Infectious Diseases, v.13, n. 3, p. 203-206, 2009.

TRISTÃO, W.; RIBEIRO, R. M. P.; OLIVEIRA, C. A; BETIOL, J. C; BETTINI, J. S. R. Estudo epidemiológico do HPV na mucosa oral por meio de PCR. Brazilian Journal of Otorhinolaryngology, v. 78, n. 4, p. 66-70, 2012.

VERONESI, R.; FOCACCIA, R. Tratado de infectologia. v. 2, 3. ed. São Paulo: Editora Atheneu, p. 1269, 2005. 